determining factor in the weather at any place. The unfailing agreement shown by these calculations arouses suspicion. On closer examination, we find that the signs of the corrections vary quite arbitrarily, while at least five different methods of correcting for declination occur in the text. Results based on such foundations cannot inspire much confidence, even though a fair agreement between predictions and Greenwich records is claimed. The more obvious method of exhibiting the similarity of meteorological conditions under similar astronomical conditions by comparing the corresponding isobaric charts does not appear to have occurred to Mr. Clements. We commend this method to the attention of those who have leisure to devote to a detailed examination of a mode of dealing with meteorology that recurs from time to time.

Bis an's Ende der Welt! Astronomische Causerien. Third Edition. Pp. 212. By Prof. F. J. Studnička. (Prague: Published by the Author, 1903.) THIs book, which was dedicated to the celebration of Christian Doppler's hundredth birthday, has reached a third edition. It is written in the form of a conversation among men of various professions meeting socially together every day with the intention of conveying in popular language many astronomical ideas. "To the end of the Universe" is the subject of a dream which one of the members of this convivial party, Carpenter by name and astronomer by profession, had dreamt, and the narrative is his account of this dream to his companions, subject, of course, to many interruptions by one or other of them seeking more information or more detailed explanation.

The author has quite succeeded in his object, and the book will be found to contain an admirable exposition of some of the more general astronomical topics. Being printed in large and Roman type, it should find many readers in this country.

Die radioactiven Stoffe nach dem gegenwärtigen Stande der wissenschaftlichen Erkenntnis. By Karl Hofmann. Pp. 54. (Leipzig: Ambrosius Barth, I903.) Price I.60 marks.

THIs book contains a concise account of the discovery and subsequent investigation of the radio-active elements by Becquerel, the Curies, Rutherford and others. It is written mainly from a chemical standpoint, and many of the effects which have been accurately measured, especially by Rutherford, are referred to as though they had been merely observed and not measured. For example, Rutherford has shown that the radio-activity of thorium-X dies away with time according to the formula $e^{-k t}$, where $t$ is the time and $k$ a constant, but Hofmann merely mentions that the activity dies away. The book contains references to the original papers published before the latter half of 1902 , and should prove useful to those wishing to study the subject.

H. A. W.

Carnet de Notes d'un Voyageur en France. Par A. C. Poiré. Pp. viii + I69. (London: Macmillan and Co., Ltd., I903.) Price Is. $6 d$.

M. PoIré intends this note-book for boys who will in the future be merchants and manufacturers. The provinces and important commercial centres of France are described only from industrial, commercial and agricultural points of view; historical, administrative and geographical details have been omitted as being unnecessary for the particular class of student for whom the book is written.

At the bottom of each page is a vocabulary of difficult or unusual French words. By the time the student has worked through the volume he will not only have much improved his knowledge of French, but have acquired considerable acquaintance with the characteristics of different parts of France.
LETTERS TO THE EDITOR.

TThe Editor does not hold himself responsible for opinions expressed by his correspondents. Neither can he undertake to return, or to correspond with the writers of, rejected manuscripts intended for this or any other part of NATURE. No notice is taken of anonymous communications.]

\section{Radium Emission.}

CONCERNING the recently discovered heat emission from radium, it is perhaps worth noting that it appears to be connected with, and is probably an immediate consequence of, the remarkable observation by Rutherford that radium emits massive positively-charged particles, which are prob. ably atoms, with a velocity comparable to one-tenth of the speed of light (see Phil. Mag., February, 1893).

Because it is easy to reckon that the emission of a million heavy atoms per second, which is a small quantity barely weighable in a moderate time such as a few weeks (being about the twentieth part of a milligramme per century), with a speed equal to one-tenth that of light, would represent an amount of energy equal to one thousand ergs per second; that is to say, would correspond to heat enough to melt a milligramme of ice every hour. And inasmuch as these atoms are not at all of a penetrating kind, but are easily stopped by obstacles, they would most of them be stopped by a small thickness of air, and their energy would be thus chiefly expended in the immediate proximity of the source, which source would thereby tend to be kept warm.

It would appear on this view as if by enclosing a bit of radium in a small chamber formed of massively obstructing non-conducting walls that it could be made quite hot; provided always that the assumed necessary stimulus, or external supply of molecular energy, could get at it uninterruptedly.

If, in the open, the rate of escape of heat were such that on the average it accumulated for one minute before escaping, the temperature of source and ambient air, with an assumed heat-capacity equal to that of one milligramme of water, would amount to one and a half degrees centigrade.

March 28 . Oliver LODGE.

\section{Radio-activity of Ordinary Materials.}

IN connection with the article by Mr. Strutt on this subject in Nature of February 19, and the letter by Prof. J. J. Thomson in the following week, it may be of interest to mention some work along similar lines that has been in progress in the McGill Physical Laboratory since September last.

At the same meeting of the American Physical Society in Washington last December, at which the interesting paper of Dr. MacLennan and Mr. Burton, referred to by Prof. J. J. Thomson, was presented, an account was given by Mr. H. L. Cooke and myself of some results showing that a very penetrating radiation was given off from the walls of buildings and from the surface of the earth itself.

The primary object of this investigation was to see if the natural ionisation of air observed in closed vessels was due, in part at least, to an external radiation which passed through the walls of the vessel. For this purpose the rate of discharge of a gold leaf electroscope in a brass vessel of about I litre capacity was observed. When the closed vessel was surrounded by thick screens of lead and iron, the rate of discharge was reduced about 30 per cent. A similar effect was observed when the electroscope was immersed in a deep water tank. No further reduction of the discharge was observed when the electroscope was surrounded with five tons of lead. These results showed conclusively that about 30 per cent. of the ionisation in closed vessels was due to an external radiation of great penetrating power which passed readily through $\mathrm{I} \mathrm{cm}$. of lead. In a brass electroscope, surrounded by thick screens, the number of ions produced was reduced to as low as five per c.c. per second. In the course of these experiments, Mr. Cooke observed that a layer of brick round the electroscope increased the rate of discharge instead of diminishing it, pointing to the conclusion that the brick was itself radio-active. Mr. Cooke has extended these observations, using cylinders of different metals placed inside the electroscope, with results of a similar character to those already recorded by $\mathrm{Mr}$. Strutt in his article. 